\title{
Nanofibre Electrospinning Poly(vinyl alcohol) and Cellulose Composite Mats Obtained by Use of a Cylindrical Electrode
}

\author{
Anna Sutka, ${ }^{1}$ Silvija Kukle, ${ }^{1}$ Janis Gravitis, ${ }^{2}$ \\ Rimvydas Milašius, ${ }^{3}$ and Jolanta Malašauskien $\dot{e}^{3}$ \\ ${ }^{1}$ Institute of Textile Materials Technologies and Design, Riga Technical University, Riga 1048, Latvia \\ ${ }^{2}$ Laboratory of Biomass Eco-Efficient Conversation, Latvian State Institute of Wood Chemistry, Riga 1006, Latvia \\ ${ }^{3}$ Department of Textile Technology, Kaunas University of Technology, 51424 Kaunas, Lithuania \\ Correspondence should be addressed to Anna Sutka; anna.putnina@rtu.lv
}

Received 30 May 2013; Revised 6 August 2013; Accepted 14 August 2013

Academic Editor: Yu Dong

Copyright (C) 2013 Anna Sutka et al. This is an open access article distributed under the Creative Commons Attribution License, which permits unrestricted use, distribution, and reproduction in any medium, provided the original work is properly cited.

A study of nanofibre composites obtained by electrospinning from poly(vinyl alcohol) (PVA) solutions of steam exploded hemp fibres and shives is reported. A combined treatment of steam explosion (SE), ball milling, and high-intensity ultrasound (HIUS) is applied to prepare cellulose nanofibres (CNF) from hemp fibres (CNF-F) and shives (CNF-S). The reflectance Fourier transform infrared (FTIR ATR) spectroscopy is used to analyze the obtained PVA/CNF composite mats. Morphology of the PVA/CNF composites was studied by scanning electron microscopy (SEM).

\section{Introduction}

Nanofibres based on poly(vinyl alcohol) (PVA) have numerous applications in various fields such as filtration materials, biomedical applications, membranes, drug release, optics, and protective clothing [1-3]. PVA is a semicrystalline, completely biodegradable, nontoxic, water-soluble, and biocompatible polymer produced industrially by hydrolysis of poly(vinyl acetate) [4-6].

Recently, attention has been paid to modification of the PVA nanofibres by different materials, such as carbon nanotubes [7], titanium [8], silica [9], chitosan [10], collagen [11], cellulose nanocrystals $[12,13]$, and others. Reinforcement of PVA with cellulose nanocrystals (CNC) improves thermomechanical properties and reduces water absorption [12]. Development of CNC-filled nanocomposite fibres/mats generates new and specific applications such as energy-related materials, sensors, barrier films, and tissue engineering scaffolds [14].

In the present work, we combine PVA with cellulose nanofibres (CNF) obtained from hemp by electrospinning technique. To our knowledge, there has no report on the preparation of nanofibers of PVA/CNF composite. In this paper, we use CNF obtained from hemp fibers and hemp shives by combination of steam explosion (SE), ball milling, and high-intensity ultrasonication (HIUS) processing.

In recent years, much attention has been focused on reinforced PVA nanofibre production by needle electrospinning $[8,12,14-17]$. Electrospinning from needle-shaped electrode has low production rate and can be used only in laboratory scale [18]. In this research, electrospinning technique by using circular cylindrical electrode has been used for PVA/CNF composite preparation. Circular electrode has main advantage-larger production rate compared to the conventional needle electrospinning [18], and equipment modules for nanofiber production in small or high volumes are available [19].

\section{Materials and Methods}

Dew-retted hemp fibers of local variety "Purini" and shives of variety "Bialobrzeskie" grown on the experimental fields of the Latgalian Agriculture Research Center LLZC (district Vilani, Latvia) are used in this research.

Hemp fibres and shives were treated using steam explosion treatment from previous researches [20, 21], milling treatment, and high-intensity ultrasonication technique. 


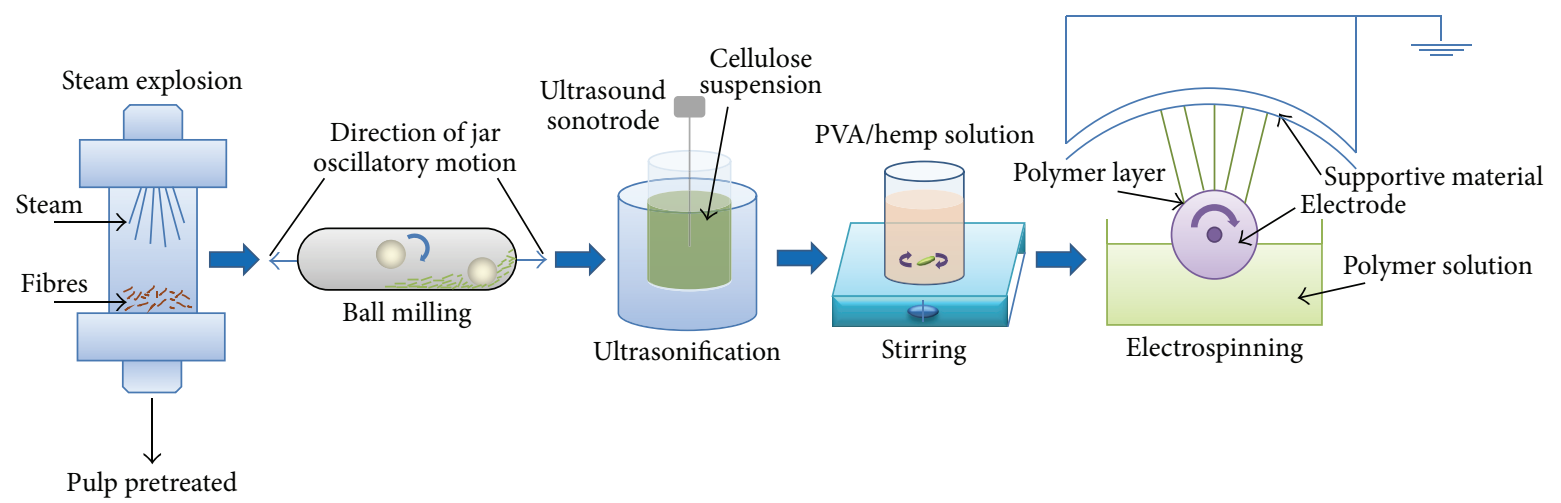

FIgURE 1: Schematic illustration of the treatment sequence of hemp fibres and shives.

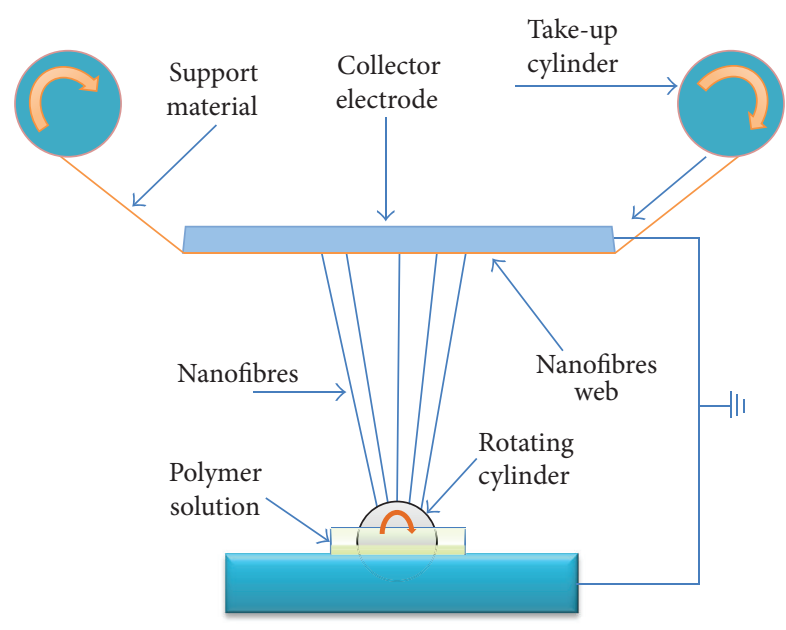

FIGURE 2: Scheme of electrospinning setup-“Nanospider."

Schematic illustration of fibers and shives treatments is shown in Figure 1.

2.1. Steam Explosion Treatment (SE). Steam explosion autohydrolysis is process which includes fast impregnation of the plant material with saturated steam in a closed reactor. The treatment proceeds at moderate temperature and pressure for a desired period of time (from some seconds to some minutes).

Severity parameter or the reaction ordinate $R_{0}$ of SE is defined by

$$
R_{0}=t * \exp \left[\frac{(T-100)}{14.75}\right],
$$

where duration of treatment ( $t$, minutes), and the temperature $\left(T,{ }^{\circ} \mathrm{C}\right)$ express the SE severity against the base or reference temperature $T_{\text {base }}=100^{\circ} \mathrm{C}$ [22].

2.2. Milling. For hemp pulp homogenization and agglomerate crushing, ball milling was performed. A Mixer Mill Retsch MM200 (Germany) at frequency $30 \mathrm{~s}^{-1}$ for 10 minutes was used.

2.3. High-Intensity Ultrasonic Treatment. The powdered fibers or shives were suspended in distilled water and treated with ultrasound (ultrasonic processor UP $200 \mathrm{Hp}, 200 \mathrm{~W}$, frequency $26 \mathrm{kHz}$, amplitude $90 \%$, sonotrode S26d14, and $\emptyset 14 \mathrm{~mm}$ ) (HIUS) for $30 \mathrm{~min}$. HIUS produces very strong mechanical oscillating power, so cellulose fibrils can be isolated from cellulose fibers by the action of hydrodynamic forces of ultrasound [23]. In order to control the process temperature, the beaker with the cellulose fiber solution was put in a water bath. The suspensions of fibers and shives after ultrasonification was mixed with PVA $8 \mathrm{wt} \%$ solution and stirred for $1 \mathrm{~h}$. PVA solution was prepared before at $70^{\circ} \mathrm{C}$ by dissolving PVA granules in distilled water and gently stirred for $2 \mathrm{~h}$. Poly(vinyl alcohol) JP-24 with degree of hydrolysis of $88 \%$ was supplied by Vam and Poval Co., Ltd. (Japan).

2.4. Viscosity Measurements. The viscosity of PVA/cellulose solutions was measured by HAAKE Viscotester 6 plus (Germany) at the temperature $20 \pm 0.5^{\circ} \mathrm{C}$.

2.5. Electrospinning. Fibers from PVA suspensions (without or with shives or fibers added) were obtained by electrospinning equipment-“Nanospider" (Elmarco, Czech Republic). While cylindrical electrode rotating, it is covered by a film of the polymer solution. When the electrostatic force overcomes the surface tension of the polymer solution, jet of polymer solution ejected from the Taylor cone. The jet moves towards the upper electrode and sets down on the spunbonded polypropylene substrate material (surface density $Q=$ $21.5 \pm 3 \mathrm{~g} / \mathrm{m}^{2}$ ). Meanwhile, the nanofibre becomes thinner; the solvent evaporates and then solidifies [24]. Scheme of electrospinning setup- "Nanospider" is shown in Figure 2.

Distance between rotating cylinder and collector electrode was $13 \mathrm{~cm}$, applied voltage was $70 \mathrm{kV}$, the temperature of the electrospinning environment was $t=20 \pm 2^{\circ} \mathrm{C}$, and the humidity was $\gamma=45 \pm 2 \%$.

2.6. Scanning Electron Microscopy (SEM). Microstructural features of the electrospun fiber samples were detected by SEM using a Field Emission Gun SEM (Tescan Mira/LMU, Czech Republic). Prior to SEM evaluation, the samples were coated with gold by means of a plasma sputtering apparatus.

2.7. Static Image Analysis. CorelDRAW Graphics Suite X6 software was used to measure the diameter and diameter 


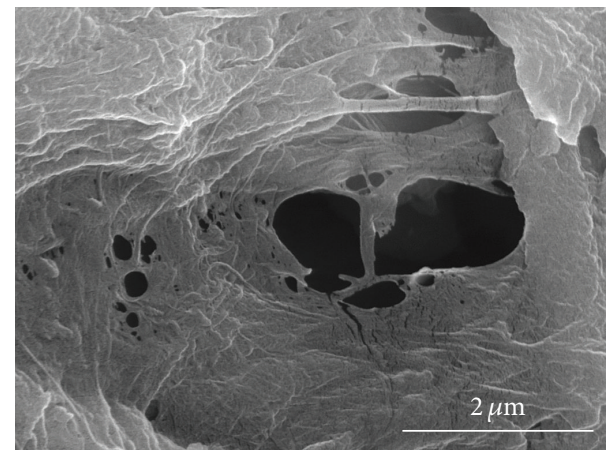

(a)

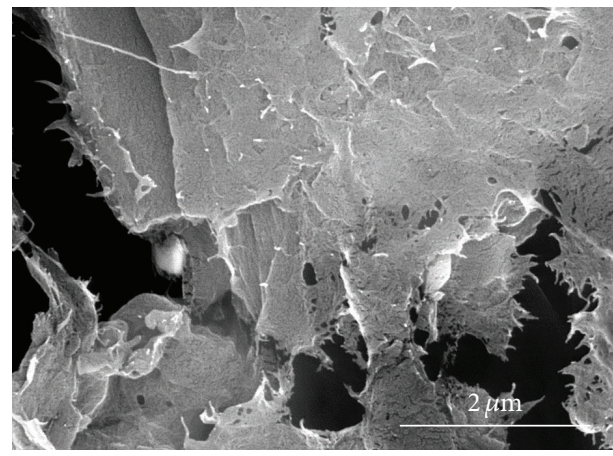

(b)

FIGURE 3: SEM micrographs of the (a) hemp fibres (CNF-F), and (b) hemp shives (CNF-S).

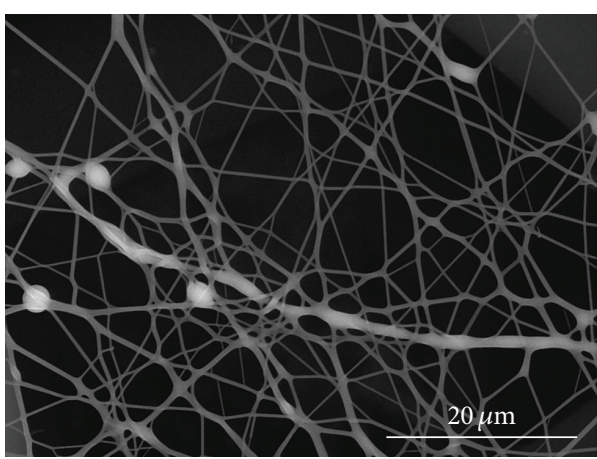

(a)

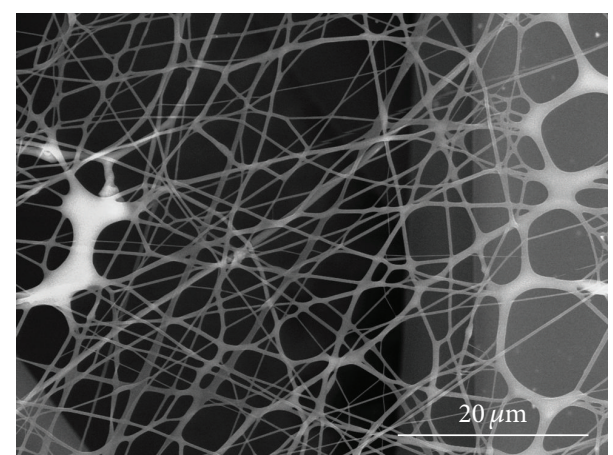

(b)

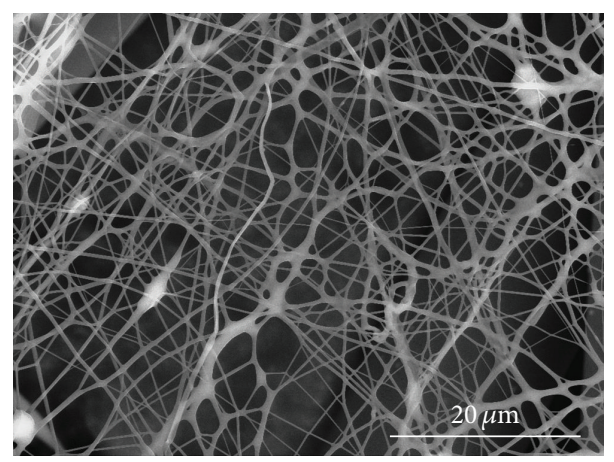

(c)

Figure 4: SEM micrographs of the (a) neat PVA fibres, (b) PVA/CNF-S 2\%, and (c) PVA/CNF-F 2\%.

distribution of electrospun fibres from two-dimensional images obtained from SEM micrographs.

2.8. Attenuated Total Reflection Fourier Transform Infrared (ATR-FTIR) Spectroscopy. ATR-FTIR was used to chemically confirm the presence of the MCC or shives cellulose inside the PVA nanofibre matrix. All spectra of the samples under investigation were recorded by Spectrum One (Perkin Elmer, UK) FTIR spectrometer in the range of $4000-400 \mathrm{~cm}^{-1}$ (resolution: $4 \mathrm{~cm}^{-1}$ ).

\section{Results and Discussion}

Steam explosion treatment conditions are shown in Table 1. After SE treatment fibres or shives were additionally washed with distilled water to remove water-soluble components and with $\mathrm{NaOH} 0.4 \mathrm{wt} \%$ solution in water to remove hemicelluloses, pectins/waxes, lignin, and oils. Then, solution was neutralized with $\mathrm{HCl}$ to precipitate lignin, filtered and additionally washed with water, and dried in air at room temperature. After drying, forms of dense pulp were made from agglomerates of the nonuniformly sized fibres.

The loss of mass during the SE treatment was found to be $\sim 14 \%$ and $\sim 23 \%$ in case of fibres and shives, respectively. A higher evaporation intensity of shives is attributed to a higher content of lignin stability which is lower during the SE treatment compared with cellulose. The mass of water-soluble components removed from fibre samples equals to $\sim 25 \%$ and $\sim 33 \%$-from shive samples. About $68 \%$ of mass is recovered 


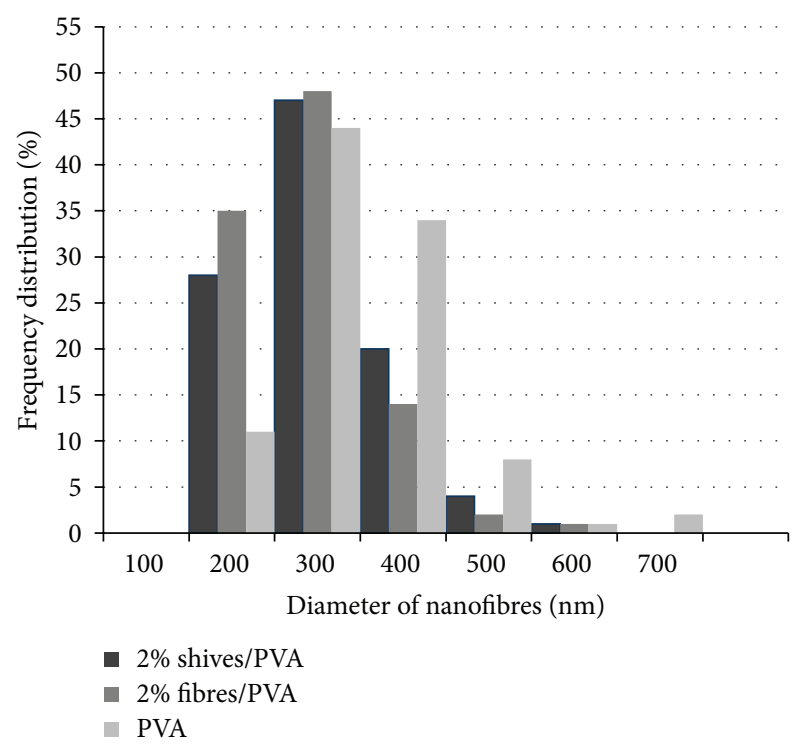

FIgURE 5: Diameter distribution of nanofibres from PVA, shives/ PVA, and fibers/PVA.

TABLE 1: Parameters of steam explosion treatment.

\begin{tabular}{lcccc}
\hline Variety & \multicolumn{4}{c}{ SE parameters } \\
& $\begin{array}{c}\text { Temperature, } \\
\text { ॰C }\end{array}$ & $\begin{array}{c}\text { Pressure, } \\
\text { bar }\end{array}$ & $\begin{array}{c}\text { Time, } \\
\text { min }\end{array}$ & $\log R_{0}$ \\
\hline $\begin{array}{l}\text { Fibres } \\
\text { ("Purini”) }\end{array}$ & 235 & 32 & 3 & 4.45 \\
$\begin{array}{l}\text { Shives } \\
\text { ("Bialobrzeskie") }\end{array}$ & 235 & 32 & 3 & 4.45 \\
\hline
\end{tabular}

in the cellulose residues of fiber samples and about $42 \%$-in case of shives (Table 2).

As found by SEM (Figure 3) studies, cellulose nanofibres (CNF) of average diameter below $100 \mathrm{~nm}$ are successfully obtained from hemp fibers and shives after combined treatment by SE, ball milling, and HIUS.

When adding CNF to the PVA polymer solution, its viscosity increases (Table 3 ). The remarkable variation in the rheological behaviour of the solutions used in our work could be due to the shear stress between fibres and polymer macromolecules. Viscosity of the solutions influences applied voltage threshold [25]. It was found that for higher polymer solution concentration higher applied voltage is necessary. In our case, viscosity for all solutions lies within the limits of the equipment for nanofibre spinning.

The morphology of electrospun fibres was studied by SEM. Figure 4 shows typical SEM micrographs for fibers obtained from PVA (a) and from PVA with $2 \%$ concentration of shives (b) and fibers (c). It was found that it is possible to obtain electrospun submicrometer fibres from used solutions. The morphology of submicrometer fibres, for example, defect concentration, shape of the fibers, and their average diameters, was not influenced by the composition of the spinning solution. However, it was found that coverage of the nanowires on the substrate material is higher for PVA/CNF composites than neat PVA.

From SEM images (Figure 4), it also can be seen that electrospun PVA and PVA/CNF melts together, thus making fraction of the composite fibres with higher diameter. This can be explained by the fact that the collecting distance was not large enough for sufficient solvent evaporation from the jet before deposition [26].

As we already concluded there is no remarkable difference between modal diameters of the PVA and PVA/CNF composite fibres, and their diameter is found to be $250 \mathrm{~nm}$ for both shives and cellulose fibres. The second modal diameters of fibres/PVA and shives/PVA correspond to the diameter range $100-200 \mathrm{~nm}$ but for PVA move to the diameter range 300-400 nm. It means that the PVA fibres are formed with average diameters above $300 \mathrm{~nm}$ (Figure 5). The addition of shives or fibers led to decreasing the average diameter of the electrospun fibers which is explained by the change in the ionic strength and conductivity of the spinning solution produced by the negatively charged cellulose. An increased electrostatic charge density of the spinning solution induced more extensive filament stretching during jet whipping [13].

To confirm the presence of hemp fibres and shives in the PVA submicrometer fibre mats, they were subjected to analysis with Attenuated total reflection Fourier transform infrared (ATR-FTIR) spectroscopy. Spectra of neat PVA polymer and combined with $1 \%$ and $2 \%$ of fibers are presented in Figure 6(a), but for shives Figure 6(b). All major peaks related to hydroxyl and acetate groups were evident in the spectra corresponding to the neat PVA. The large bands observed between 3550 and $3200 \mathrm{~cm}^{-1}$ were typical of the stretching $\mathrm{O}-\mathrm{H}$ from the intermolecular and intermolecular hydrogen bonds [13]. The vibrational band observed between 2850 and $2940 \mathrm{~cm}^{-1}$ corresponds to the stretching C-H from alkyl groups, and the peak diapason between 1730 and $1710 \mathrm{~cm}^{-1}$ was assigned to the $\mathrm{C}-\mathrm{O}$ and $\mathrm{C}-\mathrm{O}$ stretching from residual acetate groups in the PVA matrix. The presence of the peak diapason between 1085 and $1126 \mathrm{~cm}^{-1}$, corresponding to the $\mathrm{C}-\mathrm{O}$ stretching of the alcohol groups of cellulose, was clearly visible from Figure 5 of electrospun fibers/PVA composite. Intensity of peaks between this diapason increases with an increase in the fibers content of the fibers/PVA solution and the same in shives case of the peaks diapason between 1115 and $1128 \mathrm{~cm}^{-1}$, especially with the $2 \%$ shives content (Figure $6(\mathrm{~b})$ ), thus confirming formation of cellulose/PVA composites.

\section{Conclusions}

In this study, we have introduced the combination of the steam explosion, ball milling, and high-intensity ultrasonication treatments to ensure successful formation of the cellulose nanofibres with the average diameter below $100 \mathrm{~nm}$ from hemp fibres and shives. Submicron PVA fiber mats reinforced with cellulose nanofibres were prepared by electrospinning of aqueous PVA solutions using a circular cylinder as the emitting electrode. The obtained diameters of the PVA/CNF composite mats were $\sim 0.250 \mu \mathrm{m}(250 \mathrm{~nm})$. The presence of the cellulose in the PVA matrix was confirmed by ATR-FTIR 


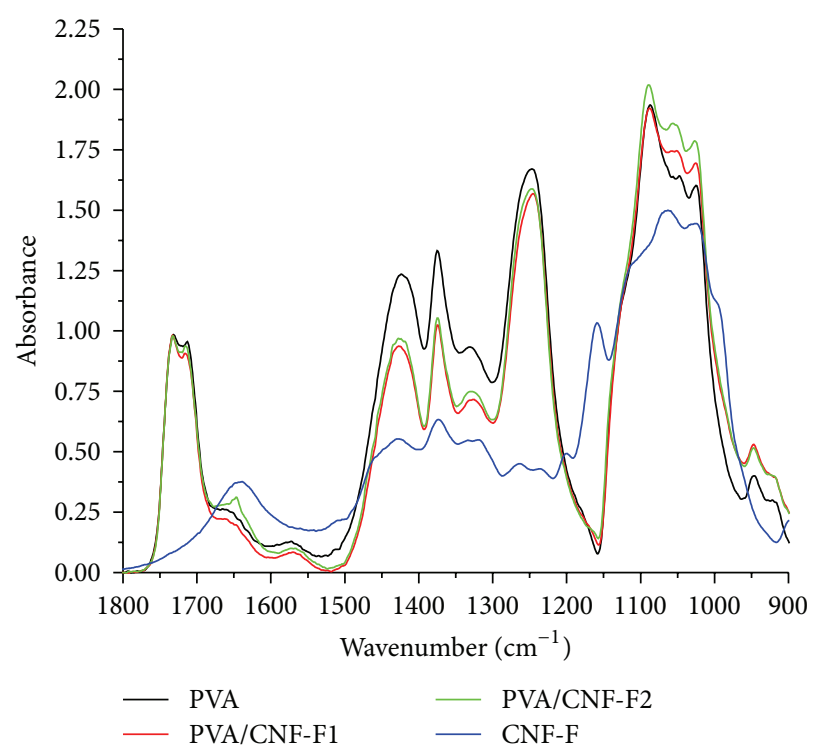

(a)

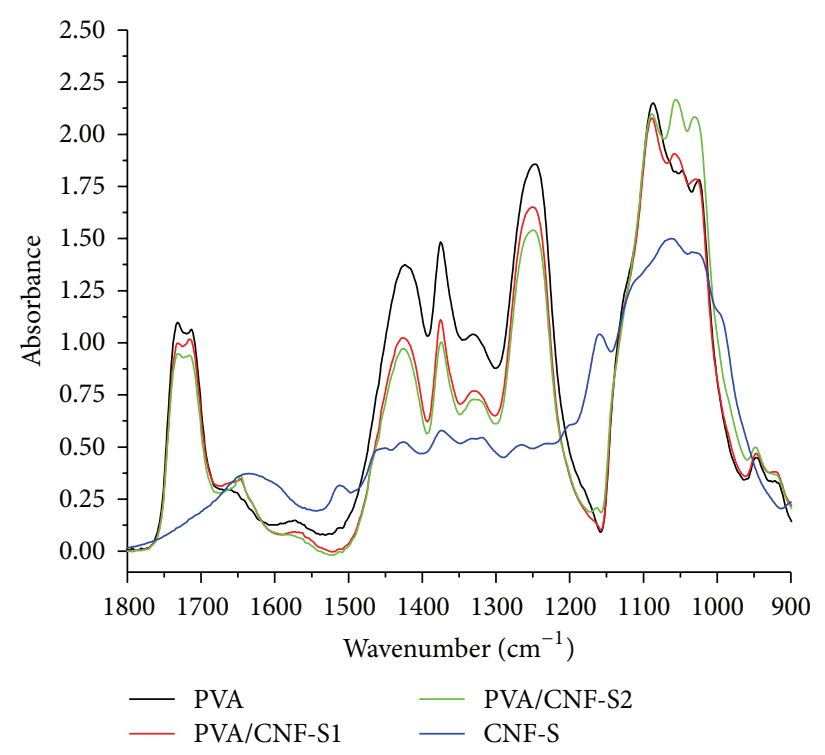

(b)

FIGURE 6: FTIR spectra corresponding to electrospun fibres and shives/PVA composites.

TABLE 2: Modes of hemp samples after SE and after treatment [21].

\begin{tabular}{lcccccc}
\hline Sample & Evaporable fractions, \% & Residue, \% & Water solub., \% & Resid. after wat., \% & Alk. solub., \% & Resid. after alk. extr., \% \\
\hline Fibres & 13.8 & 86.2 & 10.8 & 75.3 & 7.1 & 68.3 \\
Shives & 22.5 & 77.5 & 10.2 & 67.4 & 25.5 & 41.8 \\
\hline
\end{tabular}

TABLE 3: Viscosity of the polymer solutions.

\begin{tabular}{lccc}
\hline $\begin{array}{l}\text { Composition } \\
\text { of } \\
\text { polymer } \\
\text { solution }\end{array}$ & $\begin{array}{c}\text { Polymer } \\
\text { concentration, } \\
\%\end{array}$ & $\begin{array}{c}\text { Fibre } \\
\text { concentration, } \\
\%\end{array}$ & $\begin{array}{c}\text { Viscosity, } \\
\mathrm{mPa} \cdot \mathrm{s} \cdot 10^{-3}\end{array}$ \\
\hline PVA & 8 & 0 & 0.46 \\
PVA/CNF-F1 & 8 & 1 & 0.69 \\
PVA/CNF-F2 & 8 & 2 & 1.07 \\
PVA/CNF-S1 & 8 & 1 & 0.86 \\
PVA/CF-S2 & 8 & 2 & 1.8 \\
\hline
\end{tabular}

spectra of the composites. Further experiments are necessary to study physical, mechanical, thermomechanical, and water absorption properties, as well as structural stability of obtained nanocomposites.

\section{References}

[1] A. F. Spivak, Y. A. Dzenis, and D. H. Reneker, "Model of steady state jet in the electrospinning process," Mechanics Research Communications, vol. 27, no. 1, pp. 37-42, 2000.

[2] A. Theron, E. Zussman, and A. L. Yarin, "Electrostatic fieldassisted alignment of electrospun nanofibres," Nanotechnology, vol. 12, no. 3, pp. 384-390, 2001.

[3] L. Huang, K. Nagapundi, and E. L. Chaikof, "Engineered collagen-PEO nanofibers and fabrics," Journal of Biomaterials Science Polymer Edition, vol. 12, no. 9, pp. 979-993, 2001.
[4] X. Wang, C. Drew, S.-H. Lee, K. J. Senecal, J. Kumar, and L. A. Samuelson, "Electrospun nanofibrous membranes for highly sensitive optical sensors," Nano Letters, vol. 2, no. 11, pp. 1273$1275,2002$.

[5] W. J. Li, C. T. Laurencin, E. J. Caterson, R. S. Tuan, and F. K. Ko, "Electrospun nanofibrous structure: a novel scaffold for tissue engineering," Journal of Biomedical Materials Research, vol. 60, no. 4, pp. 613-621, 2002.

[6] J. A. Matthews, G. E. Wnek, D. G. Simpson, and G. L. Bowlin, "Electrospinning of collagen nanofibers," Biomacromolecules, vol. 3, no. 2, pp. 232-238, 2002.

[7] C. Fu and L. Gu, "Composite fibres from poly(vinyl alcohol) and poly(vinyl alcohol)-functionalized multiwalled carbon nanotubes," Journal of Applied Polymer Science, vol. 128, no. 2, pp. 1044-1053, 2013.

[8] P. Ahmadpoor, A. S. Nateri, and V. Motaghitalab, "The optical properties of $\mathrm{PVA} / \mathrm{TiO}_{2}$ composite nanofibres," Journal of Applied Polymer Science, vol. 130, no. 1, pp. 78-85, 2013.

[9] C. Shao, H.-Y. Kim, J. Gong, B. Ding, D.-R. Lee, and S.-J. Park, "Fiber mats of poly(vinyl alcohol)/silica composite via electrospinning," Materials Letters, vol. 57, no. 9-10, pp. 15791584, 2003.

[10] M. Ignatova, K. Starbova, N. Markova, N. Manolova, and I. Rashkov, "Electrospun nano-fibre mats with antibacterial properties from quaternised chitosan and poly(vinyl alcohol)," Carbohydrate Research, vol. 341, no. 12, pp. 2098-2107, 2006.

[11] S.-H. Teng, E.-J. Lee, P. Wang, and H.-E. Kim, "Collagen/hydroxyapatite composite nanofibers by electrospinning," Materials Letters, vol. 62, no. 17-18, pp. 3055-3058, 2008. 
[12] M. S. Peresin, Y. Habibi, A.-H. Vesterinen, O. J. Rojas, J. J. Pawlak, and J. V. Seppälä, "Effect of moisture on electrospun nanofiber composites of poly(vinyl alcohol) and cellulose nanocrystals," Biomacromolecules, vol. 11, no. 9, pp. 2471-2477, 2010.

[13] M. S. Peresin, Y. Habibi, J. O. Zoppe, J. J. Pawlak, and O. J. Rojas, "Nanofiber composites of polyvinyl alcohol and cellulose nanocrystals: manufacture and characterization," Biomacromolecules, vol. 11, no. 3, pp. 674-681, 2010.

[14] C. Zhou and Q. Wu, Recent Development in Applications of Cellulose Nanocrystals for Advanced Polymer-Based Nanocomposites by Novel Fabrication Strategies, Nanocrystals-Synthesis, Characterization and Applications, 2012, Edited by Sudheer Neralla.

[15] H. Fong, I. Chun, and D. H. Reneker, "Beaded nanofibers formed during electrospinning," Polymer, vol. 40, no. 16, pp. 4585-4592, 1999.

[16] H. Niu, J. Zhang, Z. Xie, X. Wang, and T. Lin, "Preparation, structure and supercapacitance of bonded carbon nanofiber electrode materials," Carbon, vol. 49, no. 7, pp. 2380-2388, 2011.

[17] C. Huang, Y. Tang, X. Liu et al., "Electrospinning of nanofibres with parallel line surface texture for improvement of nerve cell growth," Soft Matter, vol. 7, no. 22, pp. 10812-10817, 2011.

[18] H. Niu and T. Lin, "Fiber generators in needleless electrospinning," Journal of Nanomaterials, vol. 2012, Article ID 725950, 13 pages, 2012.

[19] Elmarco, "Nanospider Technology," http://www.elmarco.cz/ technology/nanospider\%3Csup\%3Etm\%3Csup\%3E-technology/.

[20] S. Kukle, J. Gravitis, and A. Putnina, "Processing parameters influence on disintegration intensity of technical hemp fibres," Journal of Biobased Materials and Bioenergy, vol. 6, no. 4, pp. 440-448, 2012.

[21] A. Putnina, S. Kukle, and J. Gravitis, "Steam explosion as the pretreatment method of lignocellulosic biomass," Scientific Journal of RTU, vol. 7, pp. 80-83, 2012.

[22] M. Heitz, E. Capek-Menard, P. G. Keoberle et al., "Fractionation of populus tremuloides at the pilot plant scale: optimization of steam pretreatment conditions using the STAKE II technology," Bioresource Technology, vol. 35, no. 1, pp. 23-32, 1991.

[23] Q. Cheng, Fabrication and analysis of polymeric nanocomposites from cellulose fibrils [Ph.D. dissertation], University of Tennessee, 2007.

[24] E. Adomavičiūtè, M. Adomavičiene, R. Milašius, M. Leskovšek, and A. Demšar, Magic World of Textiles Book, pp. 37-41, Proceedings of the 4rd ITC \& DC, 2008.

[25] D. Wu, X. Huang, X. Lai, D. Sun, and L. Lin, "High throughput tip-less electrospinning via a circular cylindrical electrode," Journal of Nanoscience and Nanotechnology, vol. 10, no. 7, pp. 4221-4226, 2010.

[26] H. Niu, X. Wang, and T. Lin, Needleless Electrospinning: Developments and Performances, Nanofibres-Production, Properties and Functional Applications, 2011, Edited by T. Lin. 

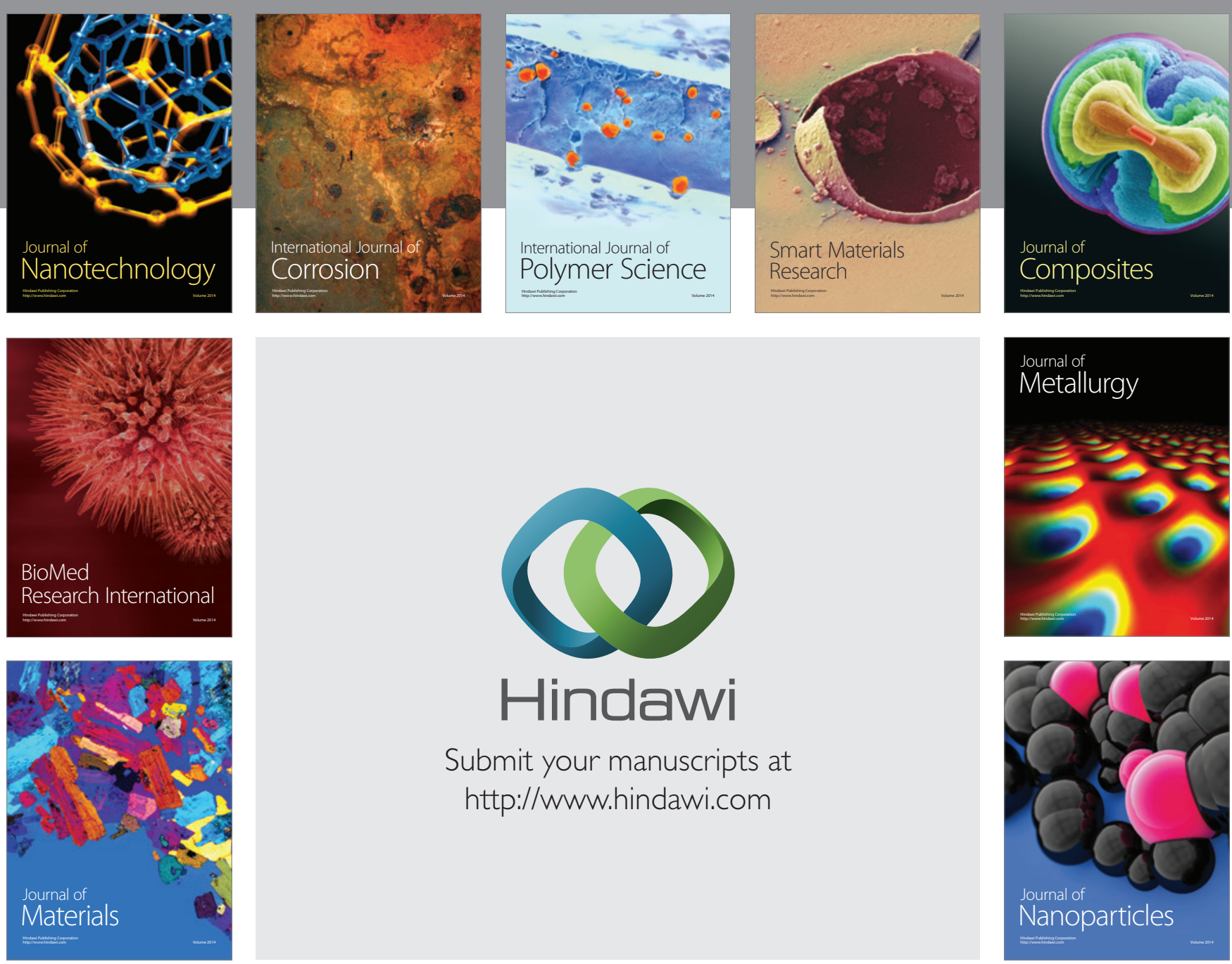

Submit your manuscripts at http://www.hindawi.com
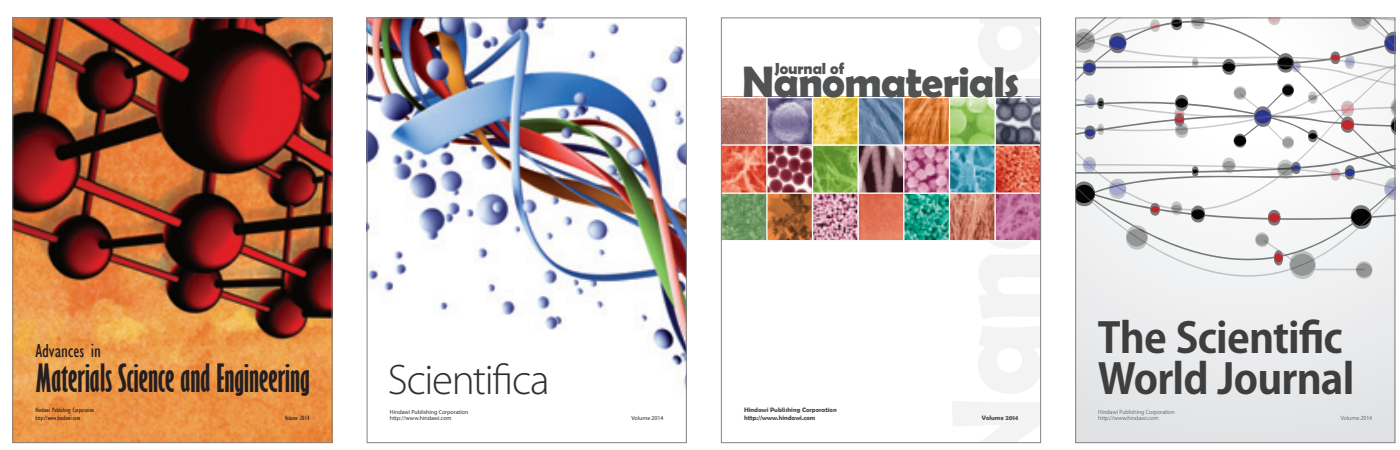

\section{The Scientific World Journal}
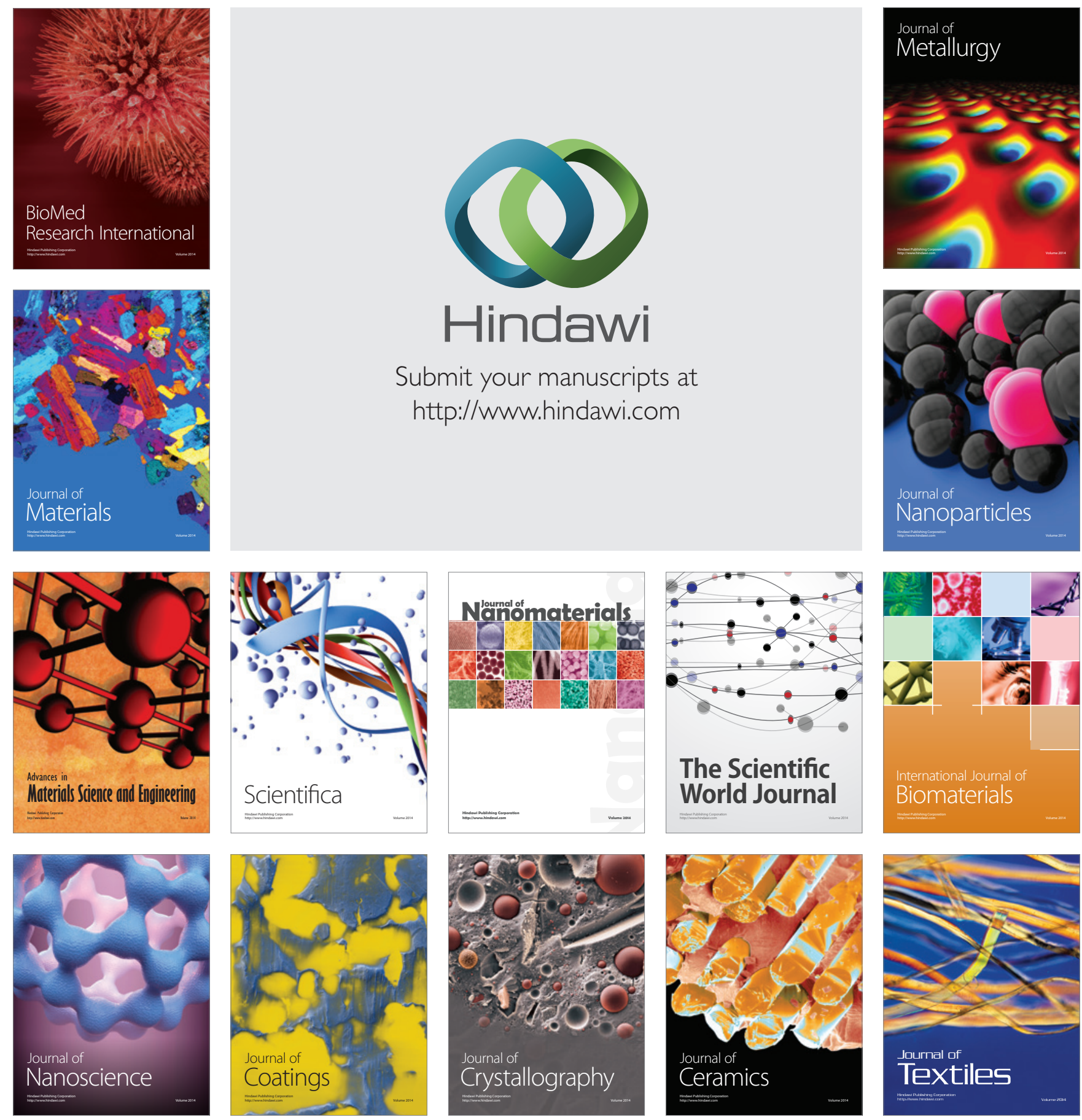